\title{
Assessing The Potential of Ion-Exchange Resin in Treating Agricultural Drainage Water Using Water Quality Modeling
}

\author{
A.T. Kandil, Maha M. Ali", A. M. K. El Saadi** and S.A. Othman** \\ Dept. of Chemistry, Faculty of Science, Helwan University, \\ *Dept. of Inorganic Chemistry at Central Laboratory and \\ ** Drainage Research Institute, National Water Research Center, \\ Cairo, Egypt.
}

\begin{abstract}
ESPITE the limitation of water resources accompanied with the increasing on water demand for agricultural expansion, water treatment and the reuse of drainage water has become an important element for Egypt's national water policy. Progressively ion exchange techniques are being used for metal extraction and pollution removal. This paper used the water quality model QUAL2K (Q2K) for evaluating the effect of using the Ion-Exchange Resin (IEXR) in treatment of Bahr Hadus drain (BHD) water. Several scenarios had been investigated by alternating the treatment of BHDs' different tributaries. These scenarios have been investigated in order to classify the best effective scenarios for enhanced pollution control on BHD. The IEXR has a major effect on the water quality of BHD. The selection of treated tributary has significant effect on the pollution control of BHD and improves its water quality.
\end{abstract}

Keywords: Ion-Exchange Resin, Bahr Hadus Drain and Water quality modeling.

Water pollution is the most serious of all environmental problems that poses a major threat to the health and well being of millions of people and global ecosystems ${ }^{(1)}$. In that regard not only the developed countries have been affected by environmental problems, but also the developing nations also suffer the impact of pollution ${ }^{(2)}$, due to disordered economic growth associated with virgin natural resources.

The traditional waste water treatment systems require high capital investments and high costs for operation and maintenance, which inhibits the ability of the governments to provide the populated centers with the appropriate treatment facilities. Wastewater effluents from household tend to be polluted by biodegradable organic matter; therefore the discharge of such waste into water courses causes serious deterioration and consumes a large amount of oxygen present in the water bodies. Whenever wastewater effluents are involved in agricultural purposes, the uses should be strictly justified. 
Water scarcity is one of the biggest challenges which face Egypt. Conservation and reuse of agricultural drainage water can cover the irrigation demand and support the national horizontal expansion plans. Although the Ministry of Water Resources and Irrigation (MWRI) of Egypt had launched a massive program for reusing drainage water in irrigation, this program is usually hindered due to water pollution. Most of the water received by the drain is from agricultural diffuse sources ${ }^{(3)}$.

El-Salam canal in Egypt was planned to mix 2.11 BCM of fresh Nile water from the Damietta branch with 1.90 and $0.43 \mathrm{BCM}$ of drainage water from BHD and El-Serw main drain, respectively. The ratio of Nile water to drainage water is about $1: 1$. This ratio is determined to reach Electrical Conductivity (EC) not more than $1500 \mu$ mhos to be suitable for cultivated crops $^{(4)}$. The project is planned to irrigate about 620,000 feddans, however, only $45 \%$ of BHD water is currently reused due to pollution issues. Water salinity of BHD should be controlled in order to increase the amount of the reuse drainage water discharged into El-Salam canal.

A continuous monitoring of wastewater plants' treatment effluents located on Bahr Hadus catchment is lacking. The discharges produce a perennial stream of poor quality water because wastewater production exceeds the treatment capacity and is mostly discharged without treatment or partially treated. It is worth mentioning that Bahr Hadus supplies El-Salam canal with $40 \%$ of its flow. The impact of domestic effluents must be ascertained with an assessment of the water quality discharged through the drain's outfall ${ }^{(5)}$.

Surface water quality models can be useful tools to simulate and predict the levels, distributions, and risks of chemical pollutants in a given water body ${ }^{(6,7)}$. Water quality models are important in predicting the changes in surface water quality for environmental management. A range of water quality models are wildly used, but every model has its advantages and limitations for specific situations ${ }^{(8)}$.

The present study aims at assessing different scenarios of possible interventions for improving the water quality of BHD. Improved commercial IEXR wastewater treatment was evaluated as a pollution control method applied on point sources inflow into BHD main stream that supplies El-Salam canal.

\section{Model description}

Water quality models are used to describe three principal phenomena: hydrological, thermal, and biochemical. These are the most classical of the three types and play an important role in water development ${ }^{(9)}$.

Referencing to Chapre \& Pelletier ${ }^{(10)}$, QUAL2K is One-dimensional River and stream water quality model intended to represent a well-mixed channel both vertically and laterally with steady state hydraulics, non-uniform steady flow, and diel heat budget and water-quality kinetics.

Egypt. J. Chem. 58, No. 5 (2015) 
QUAL2K divides the stream into unequally-spaced reaches. In addition, multiple loadings and abstractions can be input to any reach. Along a reach, the model assumes that the reaction rate coefficients, hydraulic data and incremental flow data are the same for all the computational elements within this reach.

The QUAL2K cannot take groundwater contribution of stream into account. Therefore, in some cases contaminant's concentrations were under estimation ${ }^{(11)}$.

QUAL2K simulates up to 15 water quality constituents in branching stream systems. The model uses a finite-difference solution of the advective-dispersive mass transport and reaction equation. A stream reach is divided into a number of computation elements, and for each computation element, a hydrologic balance in terms of flow, a heat balance in terms of temperature and a material balance in terms of concentration are written. Both advective and dispersive transport processes are considered in the material balance. Mass is gained or lost from the computational element by transport processes, waste water discharges, and withdrawals. The model simulates changes in flow conditions along the stream by computing a series of steady-state water surface profiles. The calculated stream-flow rate, velocity, cross-sectional area, and water depth serve as a basis for determining the heat and mass fluxes into and out of each computational element due to flow. There have been modeling studies going on to improve the accuracy of prediction, in terms of the number of parameters to be modeled, effect of critical and other available inputs of the selected model parameters ${ }^{(12)}$.

\section{Methodology}

Site description

As shown in Fig. 1, Bahr Hadus drainage system starts a few kilometers before Gemeeza Bridge (EH14) and, ends with outfall at Lake Manzalah (EH17). BHD has a total length of approximately $60 \mathrm{Km}$. Four Kilometers after its starting point, Hanut Pumping Station (EH02) extracts a considerable part of its discharge to the Hanut irrigation canal, which is approximately 17.7 m.m3/month. The main drain receives a feed of water, approximately $8.9 \mathrm{~m}$. m3/month, through the Sadaqa P.S. (EH03) on side branch.

The Nizaam branch drain, that receives 135,000 m3/day of El-Mansura city Waste Water Treatment Plant (WWTP) and about 26,000 m3/day from other WWTPs, discharges into main Hadus Drain before El-Dawar Bridge (EH15). The Beni Abied (EH06), Additional Qassabi (EH07) and Main Qassabi (EH08) P.S. discharge their water into the main Hadus Drain respectively before receiving a discharge of a branch carry the outflow of the Erad P.S. (EH10) and the Geneena P.S. (EH09), which is used partly for irrigation purposes into the main Hadus Drain. The Saft drain (EH12) (i.e., a branch of Bahr Hadus) discharges into the main Hadus before the Hadus outfall (EH17), which is located just before the siphon of El-Salam canal. Water quality of Bahr Hadus is of special importance, as part of its water will be diverted to the El-Salam canal. The remainder will be discharged into Lake Manzalah. 
For model application on the case of BHD, thirteen water samples were collected during April and June 2011 for calibration and validation.

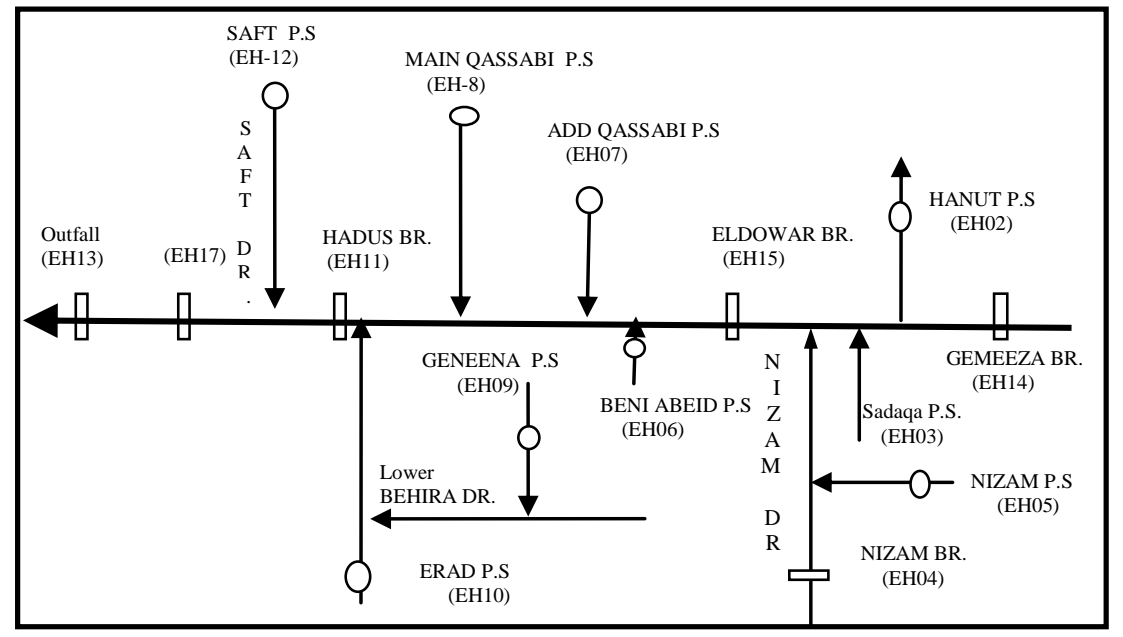

Fig. 1. Schematic diagram of Bahr Hadus drain.

Temperature, Dissolved Oxygen (DO), pH, and Electrical Conductivity (EC) were determined in-situ using a multi-probe system (i.e., Hydrolab Surveyor). Total Dissolved Solids (TDS) were determined using gravimetric techniques. Ammonia $\left(\mathrm{NH}_{4}\right)$ was determined using ammonia selective electrode method. Nitrate $\left(\mathrm{NO}_{3}\right)$ and Phosphorus (IP) were determined using Ion Chromatography (IC) (i.e., DX-500 chromatography system). Carbonates (CO3) and Bicarbonates (HCO3) were volumetrically determined by titration of a sample aliquot with a standard solution of strong acid $(0.02 \mathrm{~N} \mathrm{H} 2 \mathrm{SO} 4)$ using phenolphthalein and methyl orange as end point indicators.

\section{Model application}

The input data for the QUAL2K model were based on the field observations of drain flow and water quality samples. Meteorological data (wind speed, cloud cover, and shade) have been estimated based on the general Egyptian conditions (temperature) of the eastern Nile Delta in June of year 2011.

Model calibration tested model with known input and output information that is used to adjust model coefficients and parameters within physically acceptable ranges and the resulting predictions give the best possible fit to the observed data. The properly characterized field conditions of BHD sites resulted in a model design is calibrated and verified to a set of conditions which are representative of actual field conditions.

QUAL2K model is reviewed from hydrological and water quality points of views in order to evaluate the calibration and verification results as there are no

Egypt. J. Chem. 58, No. 5 (2015) 
universally accepted "goodness of fit" criteria that apply in all cases. However, it is attempted to minimize the difference between model simulations and measured field conditions. The difference between simulated and actual field conditions (residual) is less than 20 percent of the variability in the field data across the model domain.

The model is calibrated and verified using the water quantity and quality data of Bahr Hadus drain during April and June of year 2011. The calibration process was applied on $\mathrm{EC}, \mathrm{pH}, \mathrm{NO}_{3}, \mathrm{NH}_{4}$, Alkalinity and inorganic phosphorus parameters.

Table 1 shows the calibration results of the electrical conductivity, dissolved oxygen, alkalinity, ammonia, nitrate and phosphorus over Bahr Hadus Drain. The overall trend of the field measured data is typically following the same trend of the model results indicating a good calibration conditions for all parameters.

TABLE 1. Calibration results of Bahr Hadus Drain.

\begin{tabular}{|c|c|c|c|c|c|c|}
\hline $\mathbf{K m}$ & $\begin{array}{c}\text { Cond. } \\
(\mu \text { mohs })\end{array}$ & $\begin{array}{c}\text { DO } \\
\left(\mathrm{mg} \mathrm{O}_{2} / \mathrm{l}\right) \\
\end{array}$ & $\begin{array}{c}\text { ALK. } \\
\left(\mathrm{mg} \mathrm{CaCO}_{3} / \mathrm{l}\right)\end{array}$ & $\begin{array}{c}\mathrm{NH}_{4} \\
(\mu \mathrm{g} \mathrm{N} / \mathrm{l}) \\
\end{array}$ & $\begin{array}{c}\mathrm{NO}_{3} \\
(\mu \mathrm{g} \mathrm{N} / \mathrm{l}) \\
\end{array}$ & $\begin{array}{r}\text { Inorg. P } \\
(\mu \mathrm{g} \mathrm{P/l}) \\
\end{array}$ \\
\hline 0 & 1450 & 2.1 & 577 & 3600 & 1443 & 2295 \\
\hline 8 & 1449 & 2 & 532 & 2570 & 1800 & 1948 \\
\hline 29 & 1246 & 3.3 & 414 & 1110 & 2200 & 1990 \\
\hline 50 & 1895 & 2.5 & 359 & 2500 & 3700 & 1239 \\
\hline 55 & 2270 & 2 & 370 & 3400 & 3200 & 1390 \\
\hline
\end{tabular}

Several scenarios have been investigated in order to select the best pollution control scenario. In all scenarios, the IEXR treatment (i.e., reduction of pollution level according to laboratory application on the water quality of the tributary) had been applied on a number of point sources of BHD. $1^{\text {st }}$ scenario includes the IEXR application of treatment on EH03 water. $2^{\text {nd }}$ scenario includes the application of treatment on EH03 and EH05 waters. $3^{\text {rd }}$ scenario includes the IEXR application of treatment on EH03, EH05, and EH06 waters. $4^{\text {th }}$ scenario includes the IEXR application of treatment on EH03, EH05, EH06 and EH07 waters. $5^{\text {th }}$ scenario includes the IEXR application of treatment on EH03, EH05, EH06, EH07 and EH08 waters. $6^{\text {th }}$ scenario includes the IEXR application of treatment on the waters of EH03, EH05, EH06, EH07, EH08 and EH10. $7^{\text {th }}$ scenario includes the IEXR application of treatment of the waters of EH03, EH05, EH06, EH07, EH08, EH10 and EH12.

The main objective of scenarios application was to evaluate the possibilities of improving the water quality of Bahr Hadus drainage system for reuse. As a 
step of a comprehensive water quality management programs for BHD watershed, IEXR wastewater treatment is applied as control method over point sources of BHD to control pollutants inflow into the drain system.

\section{Results and Discussion}

As shown in Fig. 2, X-ray diffraction (XRD) pattern of commercial Ion Exchange Resin confirms that the adsorbent compound is an amorphous. The Scanning Electron Microscopy (SEM) indicates that the compound is round microsphere as seen in Fig. 3. The chemical composition of IEXR was laboratory investigated using X-ray diffraction (XRD) on a brukur advanced X-ray diffractometer model $\mathrm{D} 8$ kristalloflex (Ni-filtered $\mathrm{Cu} \mathrm{K} \alpha$ radiation ; $\lambda=1.544$ A). The EDX results are shown in Table 2 and Fig. 4 using a QUANTA FE250EDAX Genesis field emission scanning electron microscope (Holland) equipped with an energy dispersive X-ray microanalyzer (EDS).



Fig. 2. XRD pattern of adsorbent .
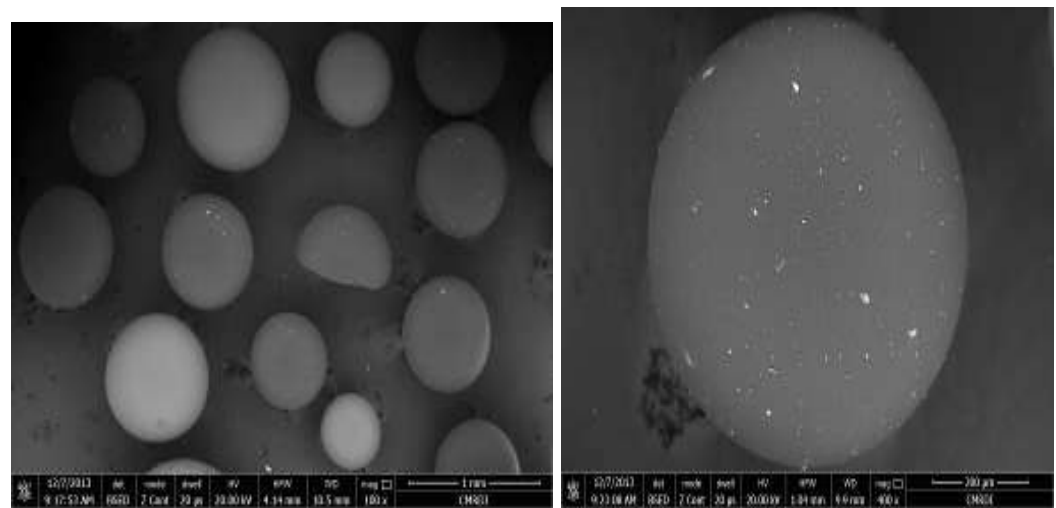

Fig. 3. Scanning Electron Microscopy (SEM) .

Egypt. J. Chem. 58, No. 5 (2015) 
TABLE 2. Energy dispersive X-ray spectroscopy of IEXR.

\begin{tabular}{|lrrrrl|}
\hline Matrix Correction: & ZAF & & \\
Element & \multicolumn{1}{l}{ Wt $\%$} & \multicolumn{1}{l}{ At\% } & Net Inte & Bgnd \\
CK & 45.44 & 62.10 & 36.08 & 0.12 \\
OK & 23.93 & 24.56 & 30.01 & 0.12 \\
FeI & 14.73 & 4.33 & 4.77 & 0.15 \\
ZnL & 1.39 & 0.35 & 1.49 & 0.17 \\
MgK & 1.29 & 0.87 & 2.89 & 0.17 \\
AlK & 2.74 & 1.67 & 6.17 & 0.20 \\
SiK & 10.48 & 6.13 & 21.81 & 0.22 \\
\hline
\end{tabular}

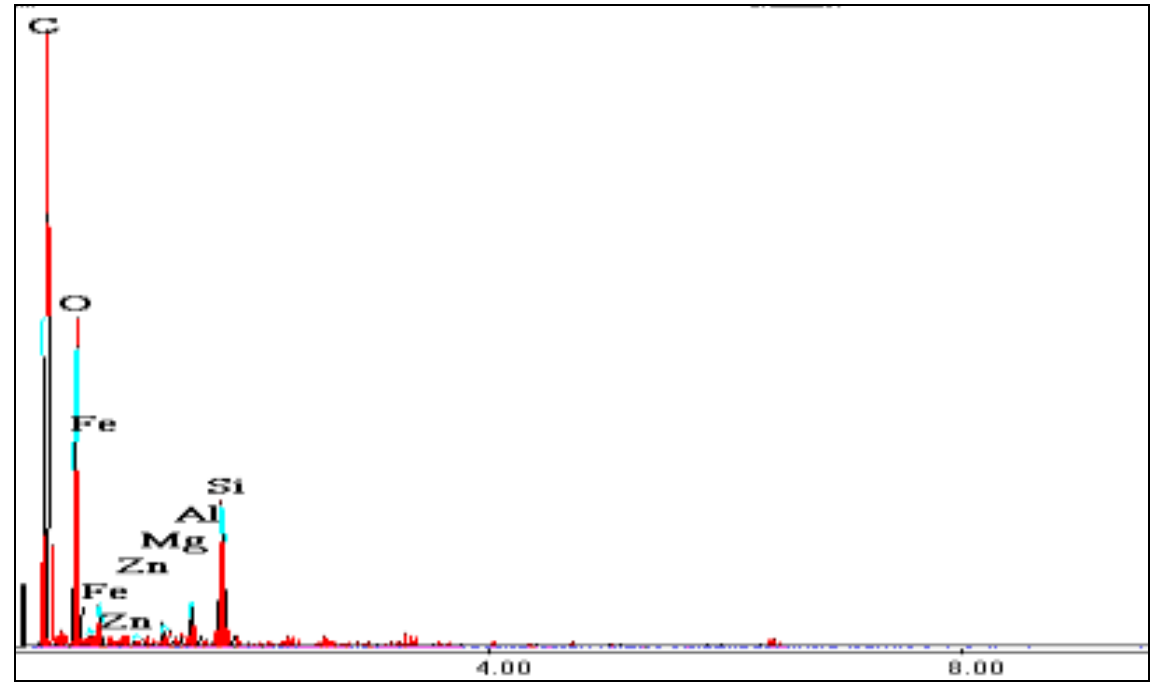

Fig. 4. Elements contained in IEXR using energy dispersive X-ray spectroscopy •

Using the water quality model (Q2K), the seven proposed main scenarios were applied on BHD generating large simulation output. Besides the base case, which describes the current water quality conditions over Bahr Hadus drain, the 7 scenarios that considered the reduction of the pollution level of tributaries using IEXR treatment application on Bahr Hadus drain, were presented on charts (5), (6), (7), (8),(9) and (10).

In general, the effect of the scenarios conditions can be seen immediately after a few kilometers of the beginning of the drain and the reduction is standing over the whole drain till it reaches the outfall.

Figure 5 represents EC concentration over the distance from the headwater of Bahr Hadus drain until its outfall. The first scenario lowered EC at the upstream and middle reaches of the drain, however and by applying the 
treatment on the other point sources (i.e., $7^{\text {th }}$ scenario) the EC concentration dropped dramatically at the downstream reach.

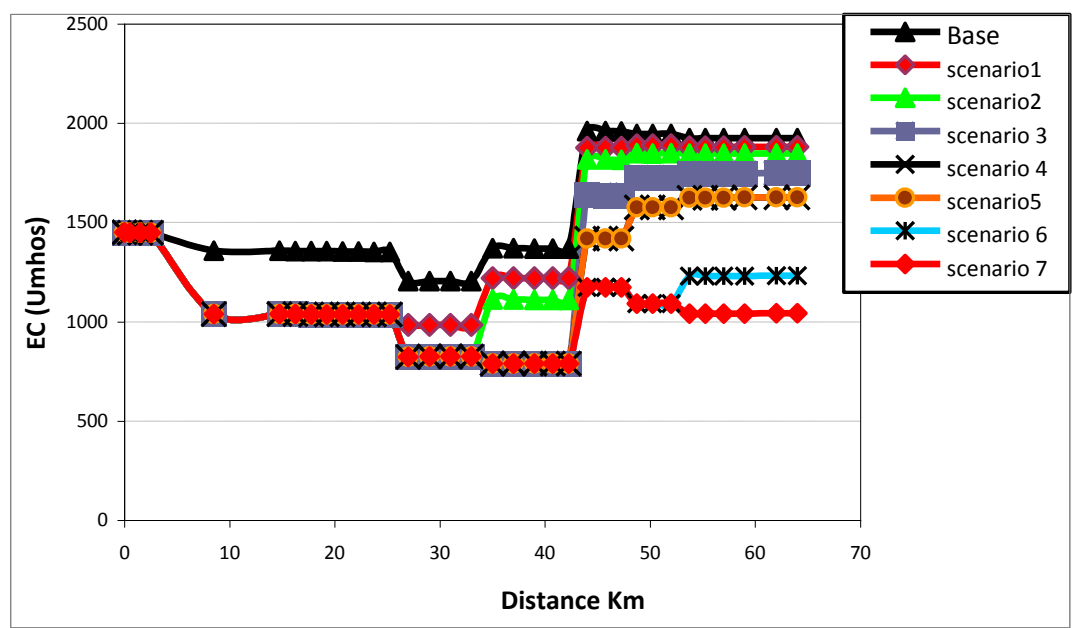

Fig. 5. Effect of EC value reduction of Bahr Hadus drain .

The $1^{\text {st }}$ scenario gave an obvious reduction in the $\mathrm{pH}$ level at the upstream reach of the drain, however, it retained original value after few kilometers (i.e., about $20 \mathrm{~km}$ ). On the other hand, the $7^{\text {th }}$ scenario gave lowered $\mathrm{pH}$ value at the middle reach of BHD lower than 6.5 (i.e., Law 48 Year 1982 limitation) as seen in Fig. 6.

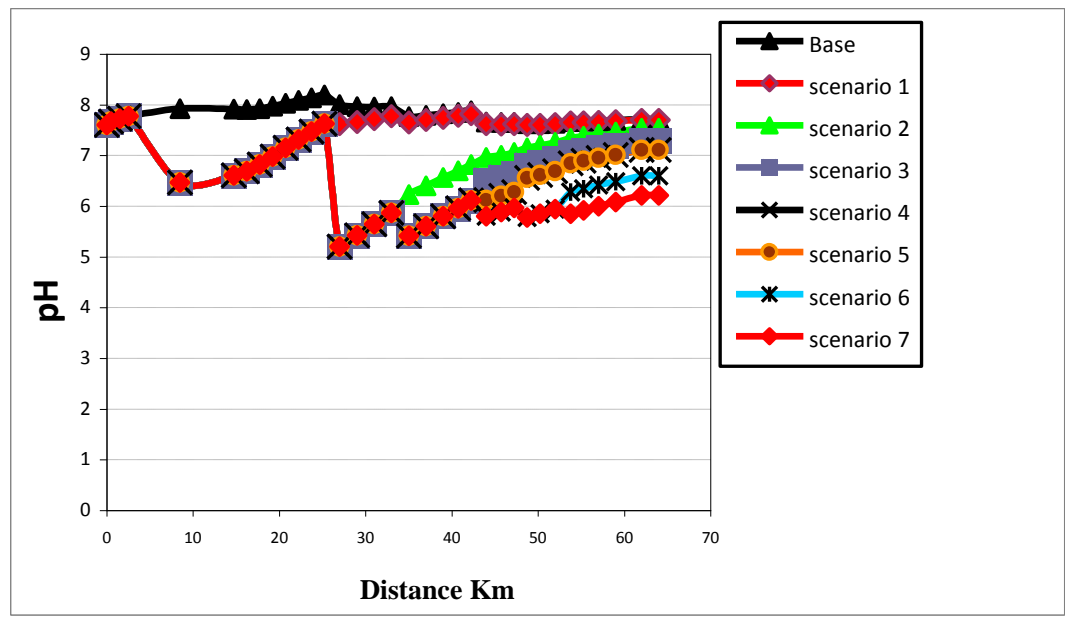

Fig. 6. Effect of pH value reduction of Bahr Hadus drain .

The IEXR has a noticeable effect on the alkalinity concentrations of the water of BHD as per scenarios applied on the drain tributaries. The $7^{\text {th }}$ scenario had 
dropped the alkalinity level from 400 to $100 \mathrm{mg} \mathrm{CaCO}_{3} / 1$ at the downstream reach of BHD as seen in Fig. 7.

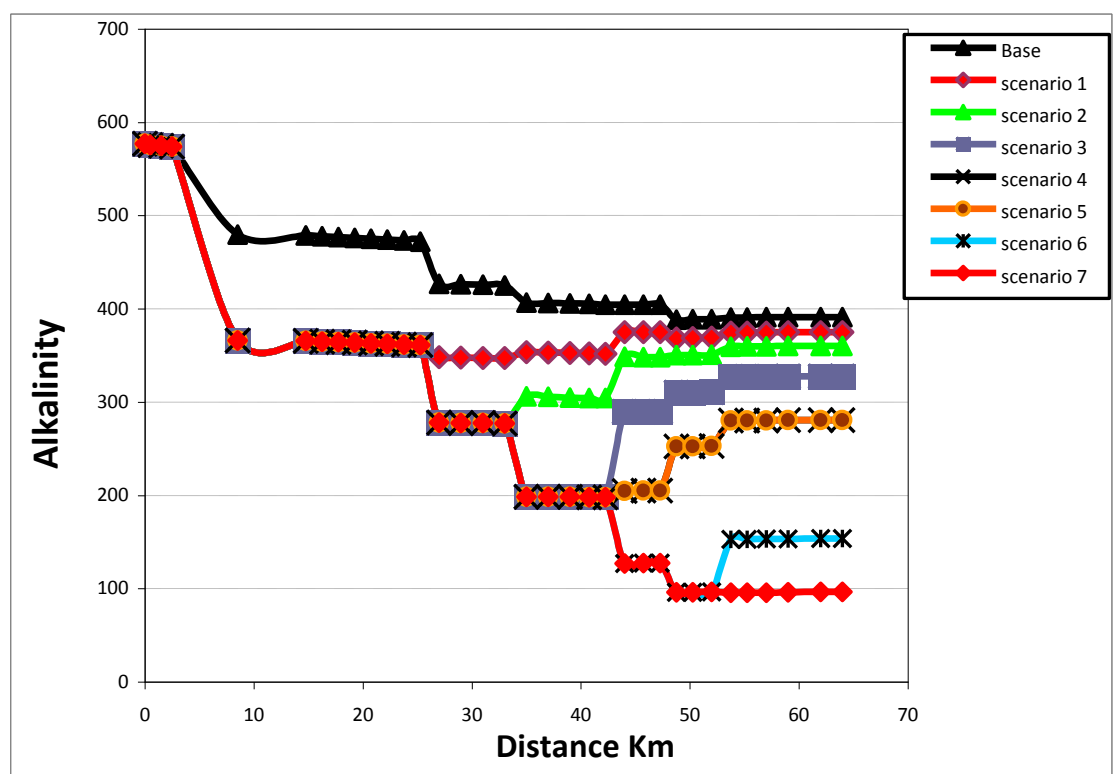

Fig. 7. Effect of alkalinity value reduction of Bahr Hadus drain .

The first 3 scenarios had no significant effect on the ammonia concentrations of the BHD. However by applying the $4^{\text {th }}$ scenario, the $\mathrm{NH}_{4}$ concentration had dropped at the downstream reach, indicating the significant effect of the treatment of additional Qassabi P.S. (EH07) on the BHD (Fig. 8) .

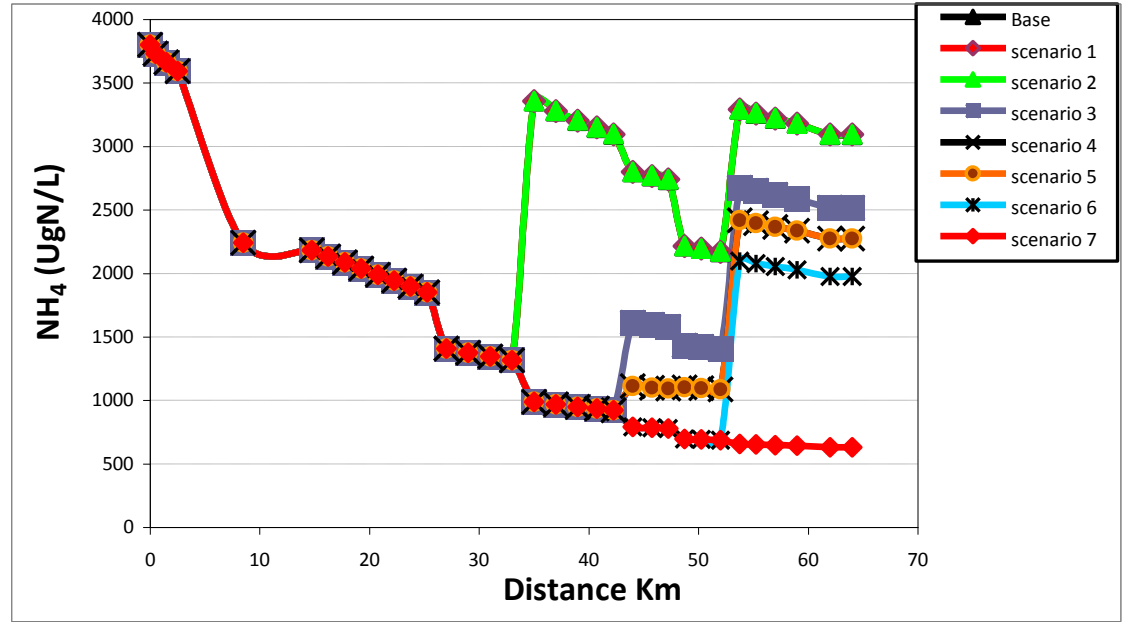

Fig. 8. Effect of $\mathrm{NH}_{4}$ value reduction of Bahr Hadus drain . 
The effect of the $1^{\text {st }}$ scenario application on $\mathrm{BHD}$ 's $\mathrm{NO}_{3}$ concentration had a temporary effect at the upstream reach. However, the $\mathrm{NO}_{3}$ concentration experiencing constant decrease in concentration by treating more tributaries' water. A significant drop in the $\mathrm{NO}_{3}$ concentration had been noticed after the $3^{\text {rd }}$ scenario, indicating the major effect of Sadaqa P.S., Nizam P.S. and Beni Ebid P.S. on the concentrations of $\mathrm{NO}_{3}$ of BHD. The $7^{\text {th }}$ scenario had decreased the concentration of $\mathrm{NO}_{3}$ from $3 \mathrm{mg} / \mathrm{l}$ to slightly above $1.5 \mathrm{mg} / \mathrm{l}$ at the end of BHD as seen in Fig. 9.

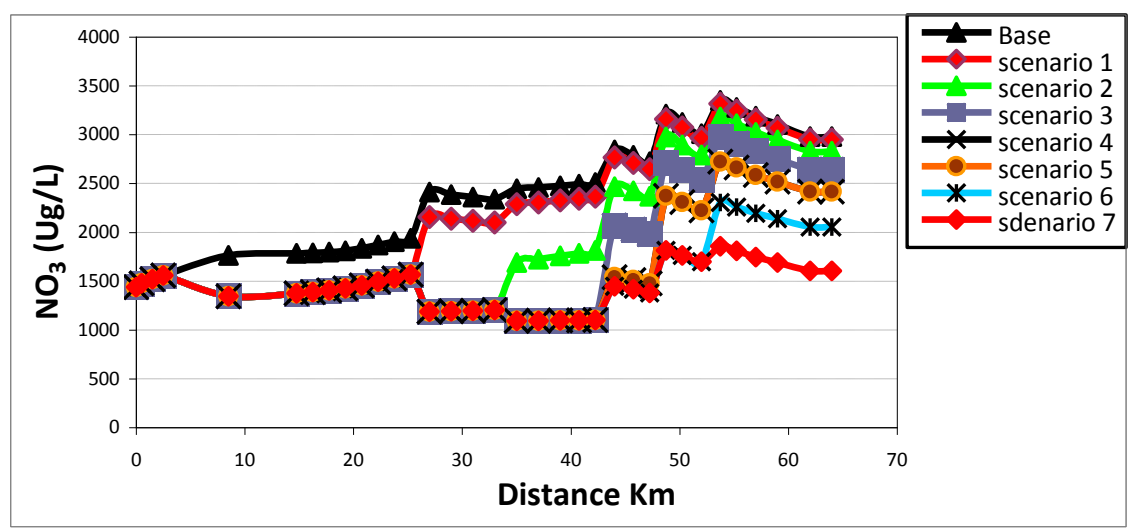

Fig. 9. Effect of $\mathrm{NO}_{3}$ concentration reduction of Bahr Hadus drain .

The $1^{\text {st }}$ scenario had also a temporary effect on the Inorganic Phosphorus (IP) at the upstream and middle reaches of BHD. However, by applying more scenarios a constant and slight effect had been noticed on the IP concentrations at the downstream reach of BHD. The $7^{\text {th }}$ scenario had dropped the concentration form $1.2 \mathrm{mg} / \mathrm{l}$ to $0.7 \mathrm{mg} / \mathrm{l}$ (Fig. 10).

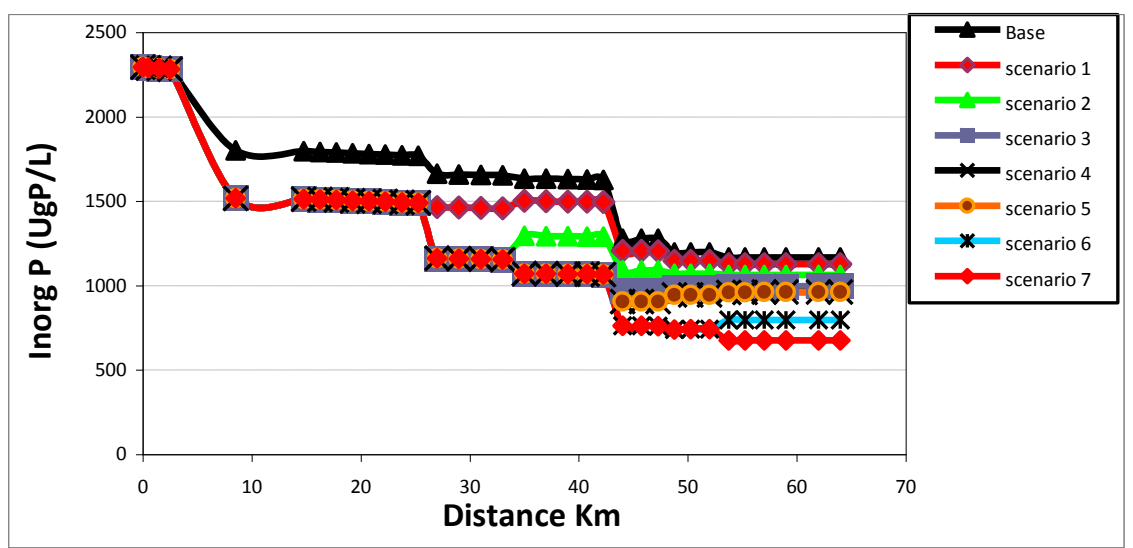

Fig. 10. Effect of scenarios application on the IP concentrations of BHD .

Egypt. J. Chem. 58, No. 5 (2015) 
Table 3 shows the percentage in reduction of different parameters at the outfall of BHD $(64 \mathrm{Km})$ due to applying each scenario. In general, the concentration of $\mathrm{EC}, \mathrm{pH}, \mathrm{NO}_{3}, \mathrm{NH}_{4}$, Alkalinity and Inorganic phosphorus parameters in the drain is decreasing with the decrease of the concentration coming from the point sources.

TABLE 3. The percentage in reduction of different parameters at the outfall of BHD.

\begin{tabular}{|l|c|c|c|c|c|}
\hline Scenarios & Cond. & ALK. & $\mathbf{N H}_{\mathbf{4}}$ & $\mathbf{N O}_{3}$ & Inorg. P \\
\hline $1^{\text {st }}$ scenario & $2.36 \%$ & $4.11 \%$ & $0.027 \%$ & $1.05 \%$ & $3.43 \%$ \\
\hline $2^{\text {nd }}$ scenario & $4.08 \%$ & $7.92 \%$ & $0.11 \%$ & $1.05 \%$ & $8.85 \%$ \\
\hline $3^{\text {rd }}$ scenario & $9.23 \%$ & $16.23 \%$ & $18.63 \%$ & $5.01 \%$ & $14.74 \%$ \\
\hline $4^{\text {th }}$ scenario & $15.54 \%$ & $28.22 \%$ & $26.42 \%$ & $11.37 \%$ & $17.63 \%$ \\
\hline $5^{\text {th }}$ scenario & $15.54 \%$ & $28 \%$ & $26 \%$ & $19 \%$ & $18 \%$ \\
\hline $6^{\text {th }}$ scenario & $24.29 \%$ & $60.74 \%$ & $36.07 \%$ & $31.17 \%$ & $31.71 \%$ \\
\hline $7^{\text {th }}$ scenario & $45.87 \%$ & $75.35 \%$ & $79.59 \%$ & $46.14 \%$ & $42.03 \%$ \\
\hline
\end{tabular}

\section{Conclusions}

The use of IEXR has perceptible effect on the treatment of drainage water of BHD, however it might drop the $\mathrm{pH}$ scale dramatically under the limitation of the environmental Law 48/1982. The salinity levels of Nizam P.S. (EH05) have significant effect on the water quality of BHD. A significant drop in the $\mathrm{NO}_{3}$ concentration had been noticed after the $3^{\text {rd }}$ scenario, indicating the major effect of Sadaqa P.S., Nizam P.S. and Beni Ebid P.S. on the concentrations of $\mathrm{NO}_{3}$ of BHD.

\section{References}

1. Alloway, B.J. and Ayers, D.C., Inorganic pollutants pp.157-264 In: "Chemical Principles of Environmental Pollution". Published by Blackie Academic and Professional, an imprint of Chapman \& Hall, 2-6 Boundary Row, London SE 18HN, U.K. ( 1997)

2. Listorti, J.A., Environmental Health Components for Water Supply, Sanitation and Urban Projects, World Bank Technical Paper No. 121, Washington, DC (1990).

3. DRI (Drainage Research Institute) Drain Pollution Sources Study for the Delta and Fayoum, Technical Report No. 56, National Water Research Center Egypt (2000). 
4. Hafez, A., Investigation of El-Salam Canal Project in Northern Sinai, Egypt, Phase-I: Environmental Baseline, Soil and Water Quality Studies. IWTC 9, Sharm El-Sheikh, Egypt (2005).

5. El Kholy, R.M.S., Drainage Water Reuse for Land Reclamation: Risks and Opportunities (Case Study El-Salam Canal, Egypt), NAWQAM Project Technical Report, NWRC, Egypt (2004).

6. Qinggai Wang, Shibei, Li, Peng Jia, Changjun, Qi, and Feng Ding, A review of surface water quality models. Hindawi Publishing Corporation The Scientific World Journal, 7, ID 231768 (2013)

7. Huang, L.B., Bai, J.H., Xiao, R., Gao, H.F. and Liu, P.P., Spatial distribution of $\mathrm{Fe}, \mathrm{Cu}, \mathrm{Mn}$ in the surface water system and their effects on wetland vegetation in the Pearl River Estuary of China. CLEAN_Soil, Air, Water, 40 (10), 1085-1092 (2012).

8. Liangliang, G.A.O. and Daoliang, L.I., A review of hydrological/water-quality models. Front. Agr. Sci. Eng. 1(4), 267-276 DOI: 10.15302/J-FASE-2014041 (2014).

9. Biswas, A.K. (Ed.) Models for Water Quality Management, McGraw-Hill Book, New York, pp. 1-7 (1981).

10. Chapra, S.C. and Pelletier, G.J., QUAL2K: A Modeling Framework for Simulating River and Stream Water Quality: Documentation and User's Manual. Civil and Environmental Engineering Dept., Tufts University, Medford, MA (2003).

11. Azzellino, A., Salvetti, R., Vismara, R. and Bonomo, L., Combined use of the EPAQUAL2E simulation model and factor analysis to assess the source apportionment of point and nonpoint loads of nutrients to surface waters. Science of Total Environment, 371, 214-222 (2006).

12. Nakhaei, N. and Shahidi, A.E., Waste water discharge impact modeling with QUAL2K, case study: the Zayandeh-rood River. International Environmental Modelling and Software Society (iEMSs). International Congress on Environmental Modelling and Software Modelling for Environment's Sake, Ottawa, Canada (2010). 
تقييم فعالية راتتج التبادل الأيوني فى معالجة مياه الصرف الزراعى بإستخدام نمذجة جودة المياه

عبد الحكيم طه قنديل ، مها محمود على" ، أيمن محمد خليل السعدى"* و سحر

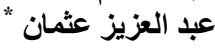

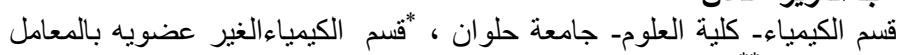

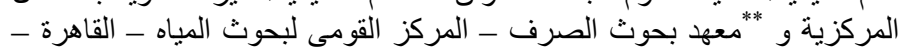

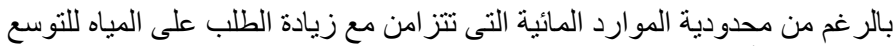

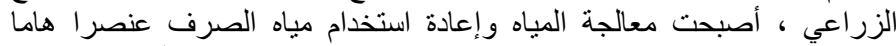

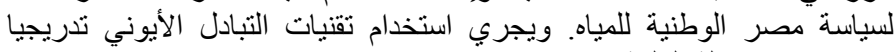
لإستخلاص و إز الة الملوثات.

فى هذا البحث ثم إستخدام Qموذج نوعية المياه لتقبيم أثر

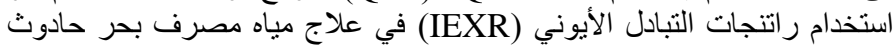
(BHD)

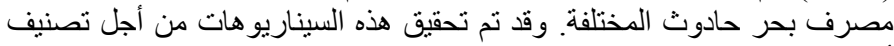

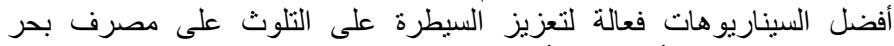

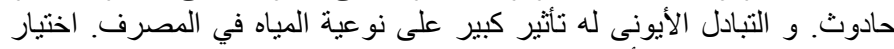

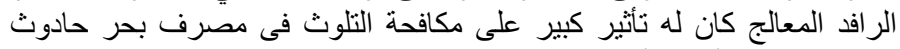
وتحسين نوعية المياه بالمصرف. لئن 